\title{
Investigation of Relationship between "Happiness and Life Quality" and "Psychological Health" in Students of Grade-2 in High School of Rasht City, Iran
}

\author{
Asieh Niksafae Tabrizi \\ Corresponding Author, Student of M.A in psychology, Tonekabon Branch, Islamic Azad University, Tonekabon, Iran
}

Bahman Akbari

Associate Professor, Department of psychology, Rasht Branch, Islamic Azad University, Rasht Iran

\section{Doi:10.5901/mjss.2014.v5n20p3105}

\section{Abstract}

The main target of this research is to determine a relationship between happiness, life quality and psychological health of students in grade-2 high school in Rasht City in 2013-2014 academic years. Statistical population in this research includes all students of grade 2 in high schools of Rasht City (865 people) who studied during 2013-2014 academic years. Statistical sample of the research included 150 female students of grade 2 in high schools of Rasht City in 2013-2014 academic years. They were picked based on Morgan Table and by means of random sampling. Correlation technique was used for analysis. Oxford's happiness Index (OHI), short-form scale of life quality developed by global health (in Iran) and Reef's psychological health scale (RspwB) were used for collecting data. Multiple regression analysis was used for verification and rejection of research hypotheses. Results showed that there is a significant relationship between happiness and life quality and psychological health in students of Rasht City High schools. In other words, students with higher levels of happiness and life quality have higher levels of psychological health.

Keywords: happiness, life quality, psychological health

\section{Introduction}

In general, some situations make human happy and some others give distress. Individual differences in happiness feeling are related to personality differences. Physical and psychological health is very important in viewpoints which consider human as the pivot of comprehensive development. In the new era, advances in science and technology and information technology have facilitated life conditions. On the other hand, rapid social changes, lifestyle change and complexities in everyday life have all threatened human psychological health and such problems have increased vulnerability of humans. Veenhoven (1997) defined happiness as a collection of emotions and cognitive evaluation of life and considers it as a degree of life quality of individuals which is evaluated as positive and is made up of cognitive, emotional, and social elements (Mablaghi, 2011). Over the past few years, happiness has received a lot of attention by researchers and sociologists (Veenhoven, 1997). Psychologists who were interested in positive psychology have focused on potential resources of positive senses like happiness (Cohen and Porsman, 2010). Happiness means a positive value a person gives to himself or herself. This construct has two aspects, one of them is emotional factors which indicate emotional experience of happiness, joy, satisfaction and other positive emotions, and the other factor is cognitive-behavioral evaluation of satisfaction with different domains of life which indicate happiness and psychological well-being (Veenhoven, 1997). Furthermore, Povet believes that individuals feel happier when they are with other people. Happiness is the scientific name for individuals' evaluations of their lives. Individuals can evaluate their lives as:"satisfaction with life or sense of content" or evaluate special aspects of their lives, for example, "satisfaction with marriage or work" or evaluate their recent emotional feelings concerned with what has happened to them: "pleasing emotions which are resulted from positive experiences of individual experiences and low levels of unsatisfactory feelings which are resulted from negative evaluations of individual experiences" (Naderifar, 2011).

Life quality includes different dimensions of physical, psychological and social health and wellbeing. Physical, personal and social factors are factors related to life quality. Physical factors include primary needs like housing, clothing, water. Personal factors include wealth, family, friends, relatives support and so on. Social factors include: individuals' 
participation in social activities (Bagheri, 2010). Psychological health and life quality is very important in teenage. Improvement of life quality in adolescence not only prevents from chronic diseases but also contributes significantly to teenagers' participation in family and social activities (WHO, 2008, as quoted from Darvishipour Kafeki, Abed Saeedi, Delavar, Saeed-al-Zakerin, 2010). The word "health" means "prevention" from physical and psychological abnormalities. So, there are some norms and deviation from these norms reflects some kind of defect and a deviated person is not considered as healthy. Health is discussed in two aspects: physical and psychological. If an individual's body and physiology undergoes a disorder, his or her body becomes unhealthy and if a person's behaviors are deviated from norms, his or her psychological system becomes defective (Morgan, Gaston \& Mock (2009)). Results of a research conducted on psychological health, religious compatibility and life quality in African-American women who received breast cancer treatment showed that there is significant relationship between psychological health and life quality aspects (physical, emotional, performance health) (Abdolkhalek, 2010). Results of a research conducted on happiness, being religious, health and possible psychological pathology in Moslem teenagers showed that all communications in both genders were significant. Girls had higher averages in religion, anxiety and depression. Average points in boys were higher in happiness, psychological health and physical health dimensions. There were significant relationships between all dimensions: religion, happiness, psychological health and physical health. All these variables had negative relationship with depression and anxiety. Kalter (2010) conducted a research titled: "membership in different types of psychological health voluntary associations of oldness", relationship between social support and happiness was verified. Mc Farland (2009) conducted a research and investigated religion and psychological health in old people. Results showed that men who had higher levels of psychological health had more religious occupations than women. Further, women who had higher levels of religious occupations were similar to those who had low to average religious activities. Further, men who had higher levels of organized religious activities had higher levels of psychological health in comparison to all other men. Jerome W.Yates (2009) conducted a research titled: "religion in patients suffering from advanced cancer" and investigated activities and religious beliefs of patients with increase in happiness, satisfaction with life and pain level in 71 patients with advanced cancer. Results showed that religious beliefs had positive correlation with satisfaction with life and religious activities. Further, it had a significant relationship with happiness and satisfaction with life. Further, religious patients reported lower levels of pain. No relationship was found between religions and lifelong in information obtained from 36 patients who are dead now. Polner (2008) conducted a research on relationship between social communications and health and reported a close relationship between God's worship and happiness. Ghaderi (2011) conducted a research on religious orientation and happiness in old people on a sample comprised of 389 old people above 60 years old, 247 men and 142 women. Results showed that relationship between internal religious orientation in old people and happiness was positive. Further, results showed that women were more religious than men. Old women had higher levels of happiness than old men and women had higher scores in both orientations. Maftoun et al (2012) conducted a research on prayer-therapy (reading Fatehe chapter and Tohid chapter) and its relationship with life quality in MS patients. Results showed that there was a significant difference between psychological health and total life quality before and after intervention. Keshavarz and Vafayeean (2012) also investigated factors affecting happiness in 453 people in Yazd City. They concluded that there is a positive relationship between age, gender, education, artistic activities, sport activities, religious activities, social relationships, optimism and happiness and there is a negative relationship between unemployment and happiness. Rohani and Manavipour (2011) conducted a research on relationship between adherence to religious practices and happiness and marital satisfaction in Mobarakeh Azad University, Isfahan, Iran. Results showed that there is a positive relationship between practice of religious beliefs and happiness and marital satisfaction. Difference between happiness in men and women was not significant and there was also no significant difference between men and women average points in religious beliefs. Balghan Abadi (2011) conducted a research on the impact of collective prayer on quality and significance of students' life. Results showed that life quality and all its dimensions (psychological health, physical health, environmental health and social relationships) in students who took part in collective prayers were significantly higher than that of those students who did not take part in prayers. Bahmani, Tamaddoni and Asgari (2011) conducted a research titled: "investigation of life quality and its relationship with religious attitude and academic performance in students of South Tehran Islamic Azad University" on 3700 students. Results showed that there is a weak positive relationship between religious attitude and life quality and this relationship was not significant statistically. In other words, no significant relationship was found between religious attitude and total life quality. Gender, age, and religion did not influence on life quality of sample group and factors like marital status, job and some academic and occupational levels of parents influenced on life quality of students. Bahrami and Ramezani Farani (2010) investigate the role of internal and external religious beliefs in psychological health and depression of old people. They found that there is a significant correlation between religious orientation and psychological health and depression of old people. In other 
words, as religious orientation point increased, disorder in psychological health and depression points also increased. Further, as points tend to internal religious direction, disorder in psychological health and depression reduced. Furthermore, there was a significant difference between psychological health, depression and religious orientation of citizen and non-citizen old people in society. This means that old citizen people had more external religious orientation and had higher levels of psychological health disorders and depression with respect to non-citizen old people. Adel khalek\&Lester (2009) conducted a research and investigated the relationship between being religious and happiness in 162 (33 male and 33 female) Kwaitian students. Results showed that there is a positive and significant relationship between religion and happiness. Therefore, use of principles of psychological health in schools requires cooperation and collaboration of school members. Therefore, schools should change their basic structures of education and strengthen fundamentals of psychological health improvement. This necessitates cooperation of parents, teachers and management. If teachers are able to recognize the symptoms of learners' problems and direct them towards problem-solving, they take an effective step in their success. Considering the above discussion, the main target of this research is to investigate relationship between happiness and life quality and psychological health in students of grade 2 in Rasht City high schools.

\section{Methodology}

\subsection{Research design}

The present research is a correlation survey.

\subsection{Statistical population and sample}

Research population in this research included all students of grade 2 in high schools of Rasht City (865 people) in 20132014 academic years. Morgan Table was used to pick 150 female students of grade 2 in high schools of Rasht City by means of simple random sampling. In simple random sampling, all members of the population have the same chance for being selected. Oxford happiness questionnaire, short-form questionnaire of life quality developed by WHO and Reef's psychological health questionnaire were distributed among sample members. No time restriction was there on responding to the questionnaires. After returning the questionnaires, data were analyzed statistically.

\subsection{Research instrument}

3 questionnaires were used to collect data from students:

1. Oxford Happiness Index (OHI): $\mathrm{OHI}$ is a very important questionnaire. 29-item Oxford's happiness index was first developed by Argil and Lu (1989, as quoted from Kar, 2004) and has a high level of validity and reliability. After consulting with Aron Back, Argil intended to reverse the sentences of Beck's depression questionnaire and therefore prepared 21 items. Then, he added 11 more items to include other aspects of happiness. Finally, he implemented the 32-item questionnaire on 8 students and asked them to judge about apparent validity after sorting of options. Therefore, the final form was reduced to 29 items after some amendments to the items and elimination of three items.

Argil, Martin and Crossland (1989) reported alpha coefficient to be eaul to 0.9 for 347 respondents and Forrenham and Browing (1990) calculated Cronbach's alpha to be equal to 0.87 for 101 respondents. Fransis, Brown, Lester and Philip (1998) conducted an inter-cultural study in England, USA, Australia and Canada and reported alpha coefficients to be equal to $0.89,0.90,0.89,0.89$, respectively. Argil et al reported Oxford index Cronbach's coefficient to be equal to 0.90 and retest coefficient after seven weeks to be equal to 0.78 . Simultaneous validity of this questionnaire was calculated to be equal to 0.43 using individuals' friends' evaluations. Further, since happiness has three parts: positive emotion, satisfaction and absence of negative emotion, correlation coefficient was estimated to be equal to 0.32 (between this questionnaire and BradBern's positive emotion scale), 0.57 (for correlation between this questionnaire and Argril's satisfaction index), and to be equal to -0.52 (for correlation between this questionnaire and Beck's depression questionnaire).

2. life quality questionnaire: 26 -question short form of WHO life quality questionnaire: the general life quality questionnaire developed by WHO comes in two forms: WHOQOL-100 and WHOQOL-BREF. Results of these two questionnaires have had satisfactory concordance with each other in different studies. This questionnaire 
was simultaneously designed in more than 15 countries and translated into different languages. Therefore, the items have the same concepts in all cultures (Bonomi et al, 2000). In Iran, this questionnaire was first translated, standardized and validated by Nejat, Holakouyee Naeeni, Mohammad, Majdzadeh (2005) (Nejat et al, 2006).

This questionnaire evaluates life quality within four areas related to health:

a) Physical health, b) psychological area, c) social relationships area, d) life environment area.

This scale (questionnaire) contains 26 questions. The first question evaluates life quality generally and the second question evaluates health generally. The next 24 questions evaluate life quality in the above four areas. This questionnaire is very common all over the world and has been translated into 40 languages and has been normalized in many countries. This questionnaire has been used in different studies. Total Cronbach's alpha is equal to 0.893, Cronbach's alpha for physical health dimension is 0.81 , for psychological health dimension is 0.76 , for social relationships dimension is 0.61 and for life quality dimension is 0.767 . This indicates favorable internal consistency. Further, it has a good level of criterion validity and discriminant validity. In order to investigate the validity of the questionnaire, defective variables impacts were eliminated from linear regression in differentiation healthy, chronic patient, non-chronic patient, chronic and non-chronic patient. Finally, validity of the questionnaire was verified. In order to calculate total point of the scale, points in the four dimensions must be added (Nejat et al, 2006).

3. Reef's psychological wellbeing questionnaire: (RspwB): this scale was first developed by Carl Reef (1980) in Wisconsin University, USA. It was revised in 2002. Psychological wellbeing scale deals with actualization of all talents of an individual and contains 6 dimensions:

1. sense of independence and autonomy: sense of competency and ability to manage one's surroundings and selection or creation of appropriate personal relationships.

2. individual growth: having a sense of continuous growth, acceptance of sentimental experiences and sense of self-efficacy.

3. positive communications with others:

4. purposefulness at life: having target in life and feeling to have a significant past life.

5. self-acceptance: having positive attitude towards oneself and having a positive view about one's past and acceptance of negative aspects of character.

6. domination over environment: domination over life management and its requirements.

This questionnaire evaluates 6 main dimensions of psychologicalwellbeing model and therefore has 6 subconstructs (each construct contains 9 clauses). This questionnaire has been prepared for the youth and adults and has an 18-item short version. Reef's questionnaire has a Likert scale from 1 (completely agree) to 6 (completely disagree). The sum of the points of the 6 dimensions is calculated as total point of psychological wellbeing. Reliability and factor analysis of this scale was equal to $81 \%$ for independence and autonomy, $79 \%$ for domination over environment, $75 \%$ for personal growth, $88 \%$ for positive relationship with others, $88 \%$ for purposefulness at life and $82 \%$ for self-acceptance. Content validity and construct validity of the research was also verified.

\section{Results}

In the present research, descriptive statistical indices (mean, standard deviation and diagram) and inferential statistical method (stepwise regression analysis) were used for data analysis in SPSS software.

\section{Conclusion and Discussion}

First hypothesis: there is a relationship between "happiness and life quality" and psychological health (autonomy) in female students of grade 2 in high schools of Rasht City". Multiple correlation coefficient and regression analysis were used for prediction and determination of happiness \& life quality based on psychological health (autonomy) in students. The results are summarized in tables 1,2, and 3.

Table 1: data for correlation and determination coefficients

\begin{tabular}{|c|c|c|c|}
\hline $\begin{array}{c}\text { Correlation coefficient } \\
\mathbf{r}\end{array}$ & $\begin{array}{c}\text { Significance level } \\
\mathbf{p}\end{array}$ & $\begin{array}{c}\text { Determination coefficient } \\
\mathbf{r}^{2}\end{array}$ & $\begin{array}{c}\text { Adjusted determination } \\
\text { coefficient }\end{array}$ \\
\hline 0.115 & 0.000 & 0.013 & 0.375 \\
\hline
\end{tabular}


Table 2: regression analysis for happiness and life quality and psychological health(autonomy)

\begin{tabular}{|c|c|c|c|c|c|}
\hline Significance level p & F value & Mean of squares & df & Sum of squares & Resource index \\
\hline & & 13.707 & 2 & 27.415 & Regression impact \\
\hline 0.000 & 0.986 & 13.900 & 147 & 2043.359 & residual impact \\
\hline & & & 149 & 2070.774 & sum \\
\hline
\end{tabular}

Table 3: results of regression coefficients

\begin{tabular}{|c|c|c|c|c|c|}
\hline significance & ratio & regression separation standard coefficient & \multicolumn{2}{|c|}{ Separation coefficient } & \multirow{2}{*}{ Predicting index } \\
\cline { 3 - 5 } $\mathbf{p}$ & $\mathbf{t}$ & Beta & Standard error & $\mathbf{B}$ & \\
\hline 0.000 & 14.143 & & 2.595 & 12.773 & constant \\
\hline 0.688 & 0.402 & 0.055 & 0.057 & 0.474 & Total happiness point \\
\hline 0.260 & 1.131 & 0.154 & 0.060 & 0.127 & Total life quality point \\
\hline
\end{tabular}

The above tables show that multiple correlation coefficient between happiness and life quality and psychological health (autonomy) is equal to 0.115 (significance level $=\mathrm{P}=0.05$ ). Further, the two variables happiness together with life quality predicts 0.601 of the variance of psychological health (autonomy) variable in students. Considering the significance of regression equation, we can predict psychological health (autonomy) using happiness and life quality points. This result conforms to the results of studies conducted by Kalter (2010) and Polner (2008). Further, results of the above research also conform to the results of studies conducted by Mqaftoun et al (2012) and Bahrami and Ramezan Farani (2010). Considering the significance of relationship between mean values, we can say with $99 \%$ of certainty that there is a relationship between "happiness and life quality" and "psychological health (autonomy)" in female students of grade 2 in Rasht City high schools. In other words, as students' happiness and life quality increase, they have higher levels of psychological health and autonomy. This can be explained by theatrical roots. Happiness refers to the amount of positive value that a person gives to himself or herself. This construct has two aspects. One of them is "emotional factors" which indicates emotional experience of happiness, joy, satisfaction and other positive emotions and the other one is "cognitivebehavioral evaluation" of satisfaction with different areas of life which indicate happiness and psychological wellbeing (Veenhoven, 1997). Happy individuals improve their skills and stick to positive events and avoid negative events. They act well in their future decision-making because they are equipped with skills like search for danger-security related information (Aspinwall , Richterand Hoffman, 2001). Physical and psychological health is very important in viewpoints which consider human as the pivot of comprehensive development. In the new era, advances in science and technology and information technology have facilitated life conditions. On the other hand, rapid social changes, lifestyle change and complexities in everyday life have all threatened human psychological health and such problems have increased vulnerability of humans. (Ta'ali, 2011).

Second hypothesis: "there is a relationship between "happiness\&life quality" and psychological health (individual growth) in students of grade 2 in high schools of Rasht City". In order to predict and determine happiness and life quality based on psychological health(individual growth), multiple correlation coefficient and regression analysis were used. The results are summarized in tables 4,5 , and 6 .

Table 4: results of determination and correlation coefficients

\begin{tabular}{|c|c|c|c|}
\hline $\begin{array}{c}\text { Correlation coefficient } \\
\mathbf{r}\end{array}$ & $\begin{array}{c}\text { Significance level } \\
\mathbf{p}\end{array}$ & $\begin{array}{c}\text { Determination coefficient } \\
\mathbf{r}^{2}\end{array}$ & $\begin{array}{c}\text { Adjusted determination } \\
\text { coefficient }\end{array}$ \\
\hline 0.196 & 0.000 & 0.038 & 0.057 \\
\hline
\end{tabular}

Table 5: regression analysis between happiness and life quality and psychological health (individual growth)

\begin{tabular}{|c|c|c|c|c|c|}
\hline Significance level $\mathbf{p}$ & F value & Mean of squares & df & Sum of squares & Resource index \\
\hline & & 50.895 & 2 & 101.791 & Regression impact \\
\hline 0.000 & 2.928 & 17.382 & 147 & 2555.149 & residual impact \\
\hline & & & 149 & 2656.940 & sum \\
\hline
\end{tabular}


Table 6: regression coefficients results

\begin{tabular}{|c|c|c|c|c|c|}
\hline significance & & regression separation standard coefficient & \multicolumn{2}{|c|}{ Separation coefficient } & Predicting index \\
\cline { 3 - 6 } $\mathbf{p}$ & ratio & Beta & Standard error & B & \\
\hline 0.000 & 10.590 & & 2.907 & 30.728 & constant \\
\hline 0.957 & 0.402 & 0.001 & 0.607 & 0.004 & Total happiness point \\
\hline 0.136 & 1.131 & 0.201 & 0.063 & 0.095 & Total life quality point \\
\hline
\end{tabular}

The tables show that multiple correlation coefficient between happiness and life quality and psychological health (individual growth) is equal to 0.196 (significance level $=0.05$ ). The two variables happiness together with life quality predicts 0.099 of the variance of psychological health (individual growth) variable in students.Considering the significance of regression equation, we can predict psychological health (individual growth) level using happiness and life quality points. These results conform to the results of studies conducted by Jroum Yits et al (2009) and Keshavarz and Vafayeean (2012). Considering the significance of relationships between mean values, it can be said (with 95\% of certainty) that there is a relationship between happiness and life quality and psychological health (individual growth) of students in grade 2 in Rasht City high schools. Mental health or psychological health is a concept which has been developed by psychologists, social sciences experts and scientists of behavioral sciences. Mental health deals with improvement of optimum interaction and reduction in deficient interaction (unstructured interaction) and psychological health has two dimensions. The first dimension involves absence of deficient interaction in psychological, emotional, behavioral and social aspects. The second dimension is optimum interactionin psychological and social dimensions. When we talk about prosperity, many people think that they need a high-level life in order to be lucky. They mistake high level of life with life quality. However, life quality has an insignificant relationship with prosperity level. Health is one of the elements of life quality which involves all dimensions of life. Therefore, it can be said that life quality has a wide concept and health is the center of gravity of life quality. Health and improvement of life quality is undoubtedly a basic human need which is also strictly strived. Scientists believe that psychological health means, on one hand, how an individual feels about him or her and others and surroundings and on the other hand, it concerns individual's compatibility, income and recognition of one's time situation. Life quality involves system of organizational performances like sentimental performance, physical performance, chemical performance, pain, tiredness and so on. One of the important dimensions of life quality is psychological dimension. In general, life quality has different definitions for different individuals but it refers to individuals' satisfaction with their lives (Rafiee, 2013).

Third hypothesis: "there is a relationship between "happiness\&life quality" and psychological health (positive communication with others) in students of grade 2 in high schools of Rasht City". In order to predict and determine happiness and life quality based on psychological health(positive communication with others), multiple correlation coefficient and regression analysis were used. The results are summarized in tables 7, 8, and 9.

Table 7: results of determination and correlation coefficients

\begin{tabular}{|c|c|c|c|}
\hline $\begin{array}{c}\text { Correlation coefficient } \\
\mathbf{r}\end{array}$ & $\begin{array}{c}\text { Significance level } \\
\mathbf{p}\end{array}$ & $\begin{array}{c}\text { Determination coefficient } \\
\mathbf{r}^{2}\end{array}$ & $\begin{array}{c}\text { Adjusted determination } \\
\text { coefficient }\end{array}$ \\
\hline 0.149 & 0.000 & 0.022 & 0.191 \\
\hline
\end{tabular}

Table 8: results of regression analysis for impact of happiness and life quality on psychological health (positive relationship with others)

\begin{tabular}{|c|c|c|c|c|c|}
\hline Significance level $\mathbf{p}$ & F value & Mean of squares & df & Sum of squares & Resource index \\
\hline & & 29.413 & 2 & 58.827 & Regression impact \\
\hline 0.000 & 1.673 & 17.583 & 147 & 2584.646 & residual impact \\
\hline & & & 149 & 2643.473 & sum \\
\hline
\end{tabular}


Table 9: results of regression coefficients

\begin{tabular}{|c|c|c|c|c|c|}
\hline \multirow{2}{*}{$\begin{array}{c}\text { significance } \\
\text { p } \\
\text { B }\end{array}$} & \multirow{2}{*}{$\begin{array}{c}\text { ratio } \\
\mathbf{t}\end{array}$} & \multirow{2}{*}{$\begin{array}{c}\text { regression separation standard coefficient } \\
\text { Beta }\end{array}$} & \multicolumn{2}{|c|}{ Separation coefficient } & \multirow[t]{2}{*}{ Predicting index } \\
\hline & & & Standard error & B & \\
\hline 0.000 & 10.918 & & 2.918 & 31.862 & constant \\
\hline 0.396 & 0.852 & 0.115 & 0.068 & 0.058 & Total happiness point \\
\hline 0.769 & 1.295 & 0.040 & 0.064 & 0.019 & Total life quality point \\
\hline
\end{tabular}

The tables show that multiple correlation coefficient between happiness and life quality and psychological health (positive relationship with others) is equal to 0.146 (significance level $=0.05$ ). the two variables happiness together with life quality predict 0.077 of the variance of psychological health (positive relationship with others) variable in students.considering the significance of regression equation, we can predict psychological health (positive relationship with others) level using happiness and life quality points. These results conform to the results of studies conducted by Abdolkhalek (2009), Velester (2009) and Rohani and Manavipour (2011). Considering the significance of relationship between mean values, it can be said (with $99 \%$ of certainty that there is a relationship between happiness and life quality and psychological health (positive communication with others) in students of grade 2 in high schools of Rasht City. Life quality is a concept which must be evaluated from different psychological and social aspects and dimensions. Torrens believes that life quality has a wide concept and that it affects all aspects of an individual's present life. These aspects involve an individual's success in achieving special conditions, present experience of health feeling and individual satisfaction (Bahmani, Tamaddoni and Asgari, 2011). Therefore, since life quality of teenagers is affected by factors like physical performance, self-care, depression and anxiety, social performance, and satisfaction with life, improvement of each of the above factors can have a positive impact on total status of life quality (Rasekh, 2010). Although educational system aims to create academic and intellectual skills and transfer knowledge to children and teenagers, it can be said with certainty that the best form of experience transfer and organized learning takes place in teenagers. Schools teach students to become socially compatible and get prepared for their future occupational and academic life. Secondary school period and high school period are very vital in a student's academic life. Approximately all activities and actions taken by human in all areas are the results of decision-making. From contemporary managerial viewpoint, decision-making is a process which concerns problem-solving and therefore, decision-making is usually called problem-solving. To put it more simply, an individual is confronted with an issue and tries to solve it by changing the conditions and tends to change the conditions to obtain expected results. Management knowledge is in the form of a collection of theories concerning organizational recognition, planning, organizing, innovation, supervision and so on and is used in the form of decision-making. In other words, all managerial duties are conducted in the form of decision-making (Sadeghpour, 2009).

Fourth hypothesis: there is a relationship between "happiness\&life quality" and psychological health (purposefulness) in students of grade 2 in high schools of Rasht City". In order to predict and determine happiness and life quality based on psychological health(purposefulness), multiple correlation coefficient and regression analysis were used. The results are summarized in tables 10,11 , and 12.

Table 10: correlation coefficients and determination coefficients results

\begin{tabular}{|c|c|c|c|}
\hline $\begin{array}{c}\text { Correlation coefficient } \\
\mathbf{r}\end{array}$ & $\begin{array}{c}\text { Significance level } \\
\mathbf{p}\end{array}$ & $\begin{array}{c}\text { Determination coefficient } \\
\mathbf{r}^{2}\end{array}$ & $\begin{array}{c}\text { Adjusted determination } \\
\text { coefficient }\end{array}$ \\
\hline 0.221 & 0.000 & 0.049 & 0.025 \\
\hline
\end{tabular}

Table 11: regression analysis for happiness and life quality and psychological health (purposefulness)

\begin{tabular}{|c|c|c|c|c|c|}
\hline Significance level $\mathbf{p}$ & F value & Mean of squares & df & Sum of squares & Resource index \\
\hline & & 55.929 & 2 & 111.585 & Regression impact \\
\hline 0.000 & 3.772 & 14.827 & 147 & 2179.615 & residual impact \\
\hline & & & 149 & 2291.473 & sum \\
\hline
\end{tabular}


Table 12: regression coefficients

\begin{tabular}{|c|c|c|c|c|c|}
\hline significance & & regression separation standard coefficient & \multicolumn{2}{|c|}{ Separation coefficient } & Predicting index \\
\cline { 3 - 6 } $\mathbf{p}$ & ratio & Beta & Standard error & B & \\
\hline 0.000 & 10.769 & & 2.680 & 28.847 & constant \\
\hline 0.396 & 1.050 & 0.140 & 0.062 & 0.065 & Total happiness point \\
\hline 0.769 & 0.690 & 0.092 & 0.059 & 0.040 & Total life quality point \\
\hline
\end{tabular}

The tables show that multiple correlation coefficient between happiness and life quality and psychological health (purposefulness) is equal to 0.221 (significance level $=0.05$ ). the two variables happiness together with life quality predict 0.105 of the variance of psychological health (purposefulness) variable in students. considering the significance of regression equation, we can predict psychological health (purposefulness) level using happiness and life quality points. These results conform to the results of studies conducted by Mac Farland (2009) and Bahmani, Tamaddoni and Asgari (2010). Considering the significance of relationship between mean values, it can be said (with 0.99 of certainty) that there is a relationship between happiness and life quality and psychological health (purposefulness) of female students of grade 2 in Rasht City high schools. Every person is influenced by psychological pressures in his or her everyday life and such pressures threaten his or her psychological and physical health. However, the way of confrontation with these pressures is important. Life quality is a multi-dimensional subject and has physical, psychological, social and spiritual aspects. This is concordant with definition of healthsince we call health as complete physical, psychological, social and spiritual wellbeing. Life quality is a mental and dynamic structure which compares past life conditions with recent events. According to ferrans \& powers, life quality is originated from satisfaction and dissatisfaction with life areas. Therefore, patients with similar problems may have different ideas about life quality. The psychological influence of life quality on human behavior and personality has been studied a lot over the past century and many famous psychologists and psychoanalysts like Frued, Alport, Maslaw and Froum (Tredvi, 2006) made a lot of attempts in this area and investigated relationship between life quality and happiness and psychological health. However, lifestyle and its quality has attracted the attention of more psychologists. Modern psychologists try not to focus on psychological problems but to emphasize on positive aspects of life. Psychological health education is aimed at familiarization of people with proper human communication principles and improvement of psychological and nervous problems (Shamlou, 2010).

Fifth hypothesis: there is a relationship between "happiness\&life quality" and psychological health (selfacceptance) in students of grade 2 in high schools of Rasht City". In order to predict and determine happiness and life quality based on psychological health(self-acceptance), multiple correlation coefficient and regression analysis were used. The results are summarized in tables 13, 14, and 15.

Table 13: correlation coefficients and determination coefficients results

\begin{tabular}{|c|c|c|c|}
\hline $\begin{array}{c}\text { Correlation coefficient } \\
\mathrm{r}\end{array}$ & $\begin{array}{c}\text { Significance level } \\
\mathbf{p}\end{array}$ & $\begin{array}{c}\text { Determination coefficient } \\
\mathrm{r}^{2}\end{array}$ & $\begin{array}{c}\text { Adjusted determination } \\
\text { coefficient }\end{array}$ \\
\hline 0.154 & 0.000 & 0.024 & 0.170 \\
\hline
\end{tabular}

Table 14: regression analysis for happiness and life quality relationship with psychological health (self-acceptance)

\begin{tabular}{|c|c|c|c|c|c|}
\hline Significance level p & F value & Mean of squares & df & Sum of squares & Resource index \\
\hline & & 39.275 & 2 & 78.515 & Regression impact \\
\hline 0.000 & 1.797 & 21.878 & 147 & 3216.123 & residual impact \\
\hline & & & 149 & 3294.673 & sum \\
\hline
\end{tabular}

Table 15: regression coefficients

\begin{tabular}{|c|c|c|c|c|c|}
\hline \multirow{2}{*}{$\begin{array}{c}\text { significance } \\
\text { p } \\
\text { B }\end{array}$} & \multirow{2}{*}{$\begin{array}{c}\text { ratio } \\
\mathbf{t}\end{array}$} & \multirow{2}{*}{$\begin{array}{c}\text { regression separation standard coefficient } \\
\text { Beta }\end{array}$} & \multicolumn{2}{|c|}{ Separation coefficient } & \multirow[t]{2}{*}{ Predicting index } \\
\hline & & & Standard error & B & \\
\hline 0.000 & 9.502 & & 3.255 & 30.933 & constant \\
\hline 0.193 & 1.307 & 0.177 & 0.076 & 0.099 & Total happiness point \\
\hline 0.892 & -0.217 & -0.029 & 0.071 & -0.015 & Total life quality point \\
\hline
\end{tabular}


The tables show that multiple correlation coefficient between happiness and life quality and psychological health (selfacceptance) is equal to 0.154 (significance level=0.05). the two variables happiness together with life quality predict 0.114 of the variance of psychological health (self-acceptance) variable in students. Considering the significance of regression equation, we can predict psychological health (self-acceptance) level using happiness and life quality points. These results conform to the results of studies conducted by Morgan and Gastonmac (2009) and Balghan Abadi (2011). Considering the significance of relationship between mean values, it can be said with $99 \%$ of certainty that there is a relationship between happiness and life quality and psychological health (self-acceptance) in students of grade 2 in high schools of Rasht City. We live in a world in which many dangers threat our children and reduction of threats is one of our main concerns. Health has many aspects and one of them is psychological health. In spite of advances in technology, education, nutrition, medicine and so on, our concerns are increasing. Our concerns include way of communicating with others, children's behavioral problems, the fact that why we keep distant from our relatives and why we face problems in establishment of relationship with others. Psychological does not simply investigate individuals'psychological problems but also it investigates strengths and individuals' positive aspects. This is similar to definition of health which does not emphasize only on absence of illness but also it pays attention to individuals' optimum states. Moreover, prevention is an important subject of study which has received a lot of attention by psychologists. One of the basic human needs is having relax and psychological health and also high level of life quality. This is because individuals can grow under relax and satisfaction. Psychological health depends on prevention from tense conditions because most individuals suffer from psychological insecurity, anxiety and dissatisfaction. health and improvement of life quality is undoubtedly one of the basic needs of human. Life quality involves system of organizational performances like sentimental performance, physical performance, chemical performance, pain, tiredness and so on. One of the main aspects of human life quality is psychological aspect. In general, life quality has different definitions but it usually refers to individuals' satisfaction with their lives (Rafiee, 2013).

Sixth hypothesis: there is a relationship between "happiness\&life quality" and psychological health (domination over environment) in students of grade 2 in high schools of Rasht City". In order to predict and determine happiness and life quality based on psychological health(domination over environment), multiple correlation coefficient and regression analysis were used. The results are summarized in tables 16,17 , and 18.

Table 16: correlation coefficients and determination coefficients results

\begin{tabular}{|c|c|c|c|}
\hline $\begin{array}{c}\text { Correlation coefficient } \\
\mathbf{r}\end{array}$ & $\begin{array}{c}\text { Significance level } \\
\mathbf{p}\end{array}$ & $\begin{array}{c}\text { Determination coefficient } \\
\mathbf{r}^{2}\end{array}$ & $\begin{array}{c}\text { Adjusted determination } \\
\text { coefficient }\end{array}$ \\
\hline 0.204 & 0.000 & 0.042 & 0.143 \\
\hline
\end{tabular}

Table 17: regression analysis for relationship between happiness and life quality and psychological health (domination over environment)

\begin{tabular}{|c|c|c|c|c|c|}
\hline Significance level p & F value & Mean of squares & df & Sum of squares & Resource index \\
\hline & & 59.930 & 2 & 119.859 & Regression impact \\
\hline 0.000 & 3.206 & 18.691 & 147 & 2747.634 & residual impact \\
\hline & & & 149 & 2867.493 & sum \\
\hline
\end{tabular}

Table 18: regression coefficients results

\begin{tabular}{|c|c|c|c|c|c|}
\hline \multirow{2}{*}{$\begin{array}{c}\text { significance } \\
p \\
B\end{array}$} & \multirow{2}{*}{$\begin{array}{c}\text { ratio } \\
\mathbf{t}\end{array}$} & \multirow{2}{*}{$\begin{array}{c}\text { regression separation standard coefficient } \\
\text { Beta }\end{array}$} & \multicolumn{2}{|c|}{ Separation coefficient } & \multirow[t]{2}{*}{ Predicting index } \\
\hline & & & Standard error & B & \\
\hline 0.000 & 9.988 & & 3.009 & 30.503 & constant \\
\hline 0.751 & -0.318 & -0.043 & 0.070 & -0.022 & Total happiness point \\
\hline 0.079 & 1.766 & 0.237 & 0.066 & 0.116 & Total life quality point \\
\hline
\end{tabular}

The tables show that multiple correlation coefficient between happiness and life quality and psychological health (domination over environment) is equal to 0.204 (significance level=0.05). The two variables happiness together with life quality predicts 0.138 of the variance of psychological health (domination over environment) variable in students. Considering the significance of regression equation, we can predict psychological health (domination over environment) 
level using happiness and life quality points. These results conform to the results of studies conducted by Ghaderi and Davoudi (2011). Considering the significance of difference between mean values, it can be said (with $99 \%$ of certainty) that there is a relationship between happiness and life quality and psychological health (domination over environment) in students of grade 2 in Rasht City high schools. Happiness is an ambiguous concept and its definition is difficult. One definition may be: emotion related to feelings which changes from satisfaction to deep pleasure. Dyner (2006) believes that happiness is a kind of self-evaluation and life quality (Ansari and Mir Shah Jafari, 2012). Happiness is nothing but coordination between human and life. Marten Seligman, in his book titled: "original happiness", classifies positive emotions in three categories:

- Those which are related to the past.

- Those which are related to the present.

- Those which are related to future.

Investigation of positive and negative emotional states is important in happiness investigation. Positive emotions are correlated with extraversion of personality, kindness, self-confidence, job satisfaction and marital satisfaction. In contrast, we have negative emotions and its correlated factors. Positive emotions are achievable via physical activities, enough sleep, association with people and having close friends and striving for excellent ambitions. Factor analysis studies and studies conducted on happiness revealed that happiness has two emotional and cognitive aspects. Therefore, happiness can be considered as emotional aspect of happiness and satisfaction can be considered as its cognitive aspect which is independent of each other. There are different joyful events: welcoming events, achieving special targets, being loved and praised. Results of the present research show that individuals who are happy and have higher levels of life quality have better psychological health and can influence others' behaviors so that they improve their educational status. It must be noted that students must be prepared for living in society and dealing with their problems so that they can improve their psychologicalhealth. Therefore, in such schools, human and his growth is very important so that students' spiritual growth and increase in productivity and science production and physical, mental and spiritual health can be achieved.

\section{References}

Abbas Zadeh, Fatemeh, Bagheri, A'azam, Mehran, Nahid (2011). Different dimensions of life quality in pregnant women.

Abbas Zadegan, Seyyed Mohammad. (2011). Basic concepts and principles of management, third printing, Tehran.

Ahmadvand, Mohammad Ali (2013). Psychological health, Tehran: Payam-e-Nour University. bagheri, Khosro, (2010). A review of Islamic Education, Tehran Publications.

Argil, Michael. (2002). Happiness psychology. Translated by masoud Gohari Anaraki et al (2010). Isfahan: University Jihad Publications, Isfahan Branch.

Argyle, M, 8 L . U.L. (1989) The happiness of extraverts. Personality and individual Differences, 11 : 1011-1013

Argyle, M.,\& LU, L . (2002) . The happiness of extroverts . Journal of Personality and Indivdual Differences, 11,1011-1012.

Argyle,M., Martin,M.\& Crossland, J.(2004) Happiness an a of Personality . In J .P.Forgas \& J.M.Innes (Eds.), Recent advances in social psychology : An international perspective, (PP.180-203). North Holland: Elsevier Science publishers.

Balghan Abadi, Mostafa (2011). The impact of collective prayer on students' life quality and significance. Papers abstract of Center for Advisory.

Bahadori. (2010). Reasons for success in life, website of psychology and medicine.

Bahrami, Fazel, Ramezani Farani, Abbas. (2011). The role of internal and external religious beliefs in psychological health and old people depression.

Bahmani, Bahman, Tamaddoni, Mojtaba, Asgari. (2010). Investigation of life quality and its relationship with religious attitudes and academic performance of students of South Tehran Islamic Azad University.

Baym,A,Rerenson.T.A.Singer.j.E(2009)Handb00k of health psychology. Lawrence Erlbaum Assiciates ,publishers,mahwah . newjersey .

Car , A.(2004) . positive psychology ,The science of happiness and human strengths. New York : Brun-ner -Routledge Ltd.

Costa, Pt, Jv. Mc crae, RR. (2005). Personality disorders and the five-factor model of personality. Journal of personality disorders 4(4), 362-371).

Costa,P.T.,\&Crae, R.(1980) .Influence of extro-version and neuroticism on subjective well-being.338,668-678.

Costa, p.t., Jr. mc crae, R. R. Dye, D. A: (2005) facet scale for agreeableness and conscientiousness: Arevision of the Neo personality Inventory. Personality individual Differences, 12: 887-898.

Delavar, Ali (2010). Statistical methods in psychology and educational sciences, payam-e-Nour publications.

Keshavarz, A, vafaeean, M. (2012). Investigation of factors affecting happiness, applied psychology. Second period, number 5.

Maftoun, F, Jahangir, A, Sadeghi, J, Karbakhsh, M, farzadi, F, Khodayee, Sh. (2012). Prayer-therapy (reading out fatehe and Tohid chapter).

Maslaw, Abraham (2009). Healthy personality psychology. Translated by Shiva Rigardiyan. Tehran: Golshahi publications. 
Milanifar, Behrouz (2010). Psychological health, Tehran: Ghomi publications.

Milanifar, Behrouz. (2010). Psychological health. Tehran: Jeihoun publications.

Moballeghi, Nafiseh (2011). Comparison of effectiveness of instruction of self-expression and problem-solving on compatibility and aggression in female students of grade 1 high school, Tonekabon Islamic Azad University.

Naderifar, Nasrin (2011). Effectiveness of teaching communication skills on self-concept, self-esteem and self-expression in female students of high schools.

Noor, N.M.(1993).Work and family roles in re-lation to women well-being . Unpublished ph .D.dissertation , University of Oxford

Parker, J. D., et al.(2004) Academic achievement in high school: Does emotional intelligence matter? Personality and Individual Differences, 37, 1321-1330.

Parker, J. D., Hogan, M. J., Eastabrook, J. M., Oke, A., Wood. L. M. (2006). Emotional intelligence and student retention: Predicting the successful transition from high school to university. Personality and Individual Differences, 41, 1329-1336.

Rohani, Abbas, Manavipour, Davoud. (2011). Relationship between practicing religious customs and happiness and marital satisfaction in Mobarakeh Islamic Azad University.

Rossouw JE, Anderson GL, Prentice RL . Risks and benefits of estrogen plus progestin in healthy postmenopausal woman: principal results from the women s health initiative randomized controlled trial. J

Sapington, Andora (2010). Psychological health. Translated by Hamid Reza Hosein Shahi Baravati, third publication, Tehran, Nashr-eRavan publications.

Sarafino. E. P (2010). Health psychology:Biopsychosocial in teractions (5th Ed).new York:wiley.

Schutte, n. s., et al.(1998). Development and validation of a measure at emotional intelligence. Personality and Individual Difference, 25, 167

Segestrom, s.c. . Taylor, S.E., kemeny . M. E . 7 fahey, j.L.(1998) optisism is associated with mood, coping, and immune change in response to stress. Journal of personality and social psychology, 47.

Shaw RW . Soutte SL .Gynaecology , 3ed London, Churchill Livingstone , 2005.

Shamlou, Saeed (2010). Psychological health, seventh publication, Tehran: Roshd Publications.

Yaghmaee, farideh, Mohmmadi Shamaneh, Alavimajd, Hamid. (2010). Psychometric design of life quality questionnaire for infertile couples. 